\title{
DEQUAL: A Tool for Investigating Deliberative Qualities in Students' Socioscientific Conversations
}

\author{
Barbro Gustafsson* ${ }^{1}$ and Johan Öhman ${ }^{2}$
}

Received 22 February 2012; Accepted 22 March 2013

Doi: 10.12973/ijese.2013.208a

\begin{abstract}
School is assumed to equip students with subject knowledge and contribute to their development as human beings and democratic citizens as well. In this article, the democratic dimension of the teaching assignment is brought to the fore, and an analysis tool for investigating students' conversations on socioscientific issues that emphasises democratic aspects is presented. The DEQUAL-tool, where the acronyms stand for DEliberative QUALities, comprises both the content-related and formal aspects of the conversations, with a specific emphasis on the collective expressions of democratic qualities like questioning, consideration for others and conveying different dimensions and arguments. DEQUAL is based on an intersubjective and communicative understanding of democracy and meaning-making, and is theoretically inspired by John Dewey's and Jürgen Habermas' views on these matters. The development and function of DEQUAL is clarified using excerpts from upper secondary school students talking about how living in a certain place influences the greenhouse effect. By pointing out characteristics, strengths and weaknesses of students' group-conversations, this methodological proposal can provide further guidance for an integrative understanding of the teacher's assignment in science education.
\end{abstract}

Keywords: Socioscientific issues, SSI, deliberations, Dewey, Habermas, democracy

\footnotetext{
${ }^{1}$ Department of Education, Linnæus University, SE-351 95 Växjö, Sweden, E-mail: barbro.gustafsson@1nu.se

${ }^{2}$ School of Humanities, Education and Social Sciences, Örebro University, SE-701 82 Örebro, Sweden
} 


\section{Introduction}

Students' interest in science education is waning in industrialised parts of the world, and educational policy initiatives to renew and strengthen science teaching have been unable to revert this downward trend (cf. Osborne \& Dillon, 2008; Sjøberg \& Schreiner, 2010). This situation encourages a self-critical scrutiny of teaching practices and invites us to reconstruct and motivate the need for and value of scientific knowledge. One argument is that scientific knowledge is necessary if individual citizens in a democracy are to make good decisions on the increasingly complex issues they are faced with (Kolstø, 2001a; Millar \& Osborne, 1998). It is argued that those who have insufficient knowledge about how science and technical applications affect and are affected by the physical and sociopolitical environment are in danger of becoming disadvantaged, or, as Hodson (2003) expresses it: "effectively disempowered and susceptible to being seriously misled in exercising their rights within a democratic, technologically dependent society" (p. 374).

Mastering a certain amount of scientific content knowledge is of importance for democratic participation and active citizenship. At the same time, the ability to question, scrutinise, argue and adopt positions with regard to societal implications and social agreements is also regarded as necessary (Roberts, 2007b; Roth \& Barton, 2004).
One way of working conjunctively with science and democracy could be to arrange for student conversations on multifaceted socioscientific issues (SSI). These issues constitute opportunities for argumentation, taking a stand and making decisions, where subject-related knowledge as well as ethical and moral reflection and critical questioning can be expressed and developed. However, we believe there is a need for adaptable methods and models for formative evaluations of students' performance of SSI in relation to democratic capabilities such as critical, moral and ethical expressions and developments. The available methodological applications of peer-conversations on SSI have a primary focus on individual students' argumentation on the scientific content of the SSI, while such models to a lesser extent have embraced character proficiencies such as ethical and moral reflection and critical thinking. However, some efforts made in line with broader democratic ambitions, such as Berkowitz and Simmons advanced transaction scheme (2003, p. 131) represent valuable ideas to build on for the elaboration of manageable models for practical use. Furthermore, if one considers the understanding and development of concepts in terms of a social enterprise, as "the product of the co-construction of shared social knowledge" (Zeidler, Osborne, Erduran, Simon, \& Monk, 2003, p. 99), the assessment models should also encompass collective and formal aspects of the conversations, such as jointly expressed views, considerations and values ${ }^{1}$. It is hoped that this contribution will remedy some deficiencies concerning theoretical backings (cf. Levinson, 2006) and provide extended knowledge, based on this framework, concerning science and democracy education in terms of collaborative conversations on socioscientific issues.

The aim of this article is to introduce $\mathrm{DEQUAL}^{2}$, an analysis tool for formative investigations of DEliberative QUALities in terms of multiple aspects of democratic values in students' conversations on SSI. The research question behind DEQUAL is: How can the democratic qualities of students' group-discussions on SSI be investigated? 
The expectation is that DEQUAL will provide methodological guidance for investigating educational achievements aimed at improving active citizenship and empowerment. The tool is based on John Dewey's (1916/1999, 1922/2007, 1927/1988) and Jürgen Habermas' (1984, 1987, 1990, 1996) intersubjective and communicative understanding of democracy and meaning-making. It considers both content-related and formal aspects of the students' conversations and puts specific emphasis on the collective expressions of democratic qualities like questioning, consideration for others and deliberations relating to different dimensions and arguments. In this way, our work is distinguished from studies of socioscientific conversations that focus on how individual students use, consolidate and develop scientific knowledge and concepts (see for example Erduran, Simon, \& Osborne, 2004; Kolst $\varnothing$, 2006; Lewis \& Leach, 2006; Tytler, Duggan, \& Gott, 2001).

\section{Background}

This section deals with conceptions, policies and visions associated with education for scientific literacy. It discusses educational aims concerning abilities for democratic citizenship, such as argumentative proficiencies, critical thinking and ethical reflectivity. Practising linguistic proficiency in cooperation with and consideration for others through deliberations on socioscientific issues are highlighted as educational means with intentions to achieve democratic goals. The presented overview of assessment methods used for conversations on socioscientific issues pinpoints the position of this contribution.

\section{Science Education for Citizenship}

The democracy task aims at empowerment and responsible citizenship - but what do these proficiencies entail and how could these ambitions be reached in science education? The objectives of the reformed teaching ideas that constitute the basis of Scientific Literacy ${ }^{3}$ - projects, the STS-movement ${ }^{4}$ and visions relating to science education for all have been to encourage a greater interest and broader civic knowledge base through social contextualisation and authentic examples. The hope is that the teaching will not only focus on scientific knowledge but will also include science as a human enterprise and the uncertain dimensions of contemporary science (cf. Millar \& Osborne, 1998; Osborne \& Dillon, 2008). However, critical voices claim that these efforts do not fulfil the democratic aims and citizenship-ambitions. According to Zeidler, Sadler, Simmons and Howes (2005), the STS-vision does not provide "sufficient" psychological and epistemological growth of the child, nor the development of character or virtue" (p. 358). Therefore, science teaching should specifically "address the students' personal and individual moral and ethical development" (p. 359). Furthermore, scholars such as Roth and Barton (2004) believe that these projects and ideas do not sufficiently comprise social aspects and societal implications of science and technology, and they believe that the term "scientific literacy" can be taken a little further if science in class is regarded as "an empowerment zone where students are valued for their abilities to contribute to, critique, and partake in a just society" (p. 5, see also Linder et al., 2010).

Being able to think critically is considered as a central civic virtue in a democratic society (see for example Winch, 2006). What, then, does "critical thinking" involve and imply? Ennis (1993) describes it as: "reasonable reflective thinking focused on deciding what to believe or do" (p. 180). Another dimension of critical thinking which he points out is open-mindedness, i.e. a willingness to consider other views and a readiness to change opinion in the light of good arguments. Furthermore, as emphasised by Bailin (2002) and Kolst $\varnothing$ et al. (2006), a certain amount of background knowledge in the actual subject field is a prerequisite for being able to think critically.

In science education, critical thinking could be seen as a generic skill for using scientific knowledge and adequate evidential principles to justify scientific claims, scrutinise issues and underpin standpoints through formal logic. However, according to Winch (2006), the formal and contextindependent proficiencies of critical rationality have to be combined with personal virtues such as tolerance of other viewpoints, 
attentiveness, self-discipline, charitability and patience. He takes Ennis' definition one step further by claiming that critical rationality also requires "paying heed to the wider consequences of what one is doing" (p. 52). This would mean that students should not only be entitled and encouraged to critically examine the scientific domain but also the standards, values, norms and assumptions that are more or less implicitly manifested in information, arguments and claims. Furthermore, they should be offered opportunities to develop the personal virtues that Winch regards as indispensable for critical rationality.

\section{Socioscientific Issues}

According to Zeidler and Nichols (2009) socioscientific issues (SSI) are issues which "involve the deliberate use of scientific topics that require students to engage in dialogue, discussion, and debate. They are usually controversial in nature but have the added element of requiring a degree of moral reasoning or the evaluation of ethical concerns in the process of arriving at decisions regarding possible resolution of those issues" (p. 49). Examples of such issues are global warming, genetically modified organisms and foetal diagnostics. They are resolved through reasoning processes, individual or at group level, where assertions, reasons and positions are made plain. Since they seldom have given answers in terms of "right" or "wrong" and, additionally, decision-making is influenced by social norms and individual values, they invite an exchange of views and value-influenced positions. Roberts (2007a) means that socioscientific issues offer opportunities to specifically deal with scientific literacy, which leads us to look more closely at their characteristics and how they link into the democratic aim within science education. It is therefore considered that SSI could be vehicles in an education for citizenship by offering opportunities to practice and develop skills such as challenging questions, critical scrutiny and thoughtful decision-making (Kolstø, 2000, 2001a; Ratcliffe \& Grace, 2003; Sadler, Barab, \& Scott, 2007) and thereby strengthen "the power of citizens to challenge orthodoxy and to participate in decisions affecting their lives" (Bingle \& Gaskell, 1994, p. 198).

\section{Assessment Methods for Conversations on SSI}

In this section, a general review of the empirical research concerning students' conversations about SSI is presented. The emphasis is on their methodological approaches in relation to our specific interest for investigations of democratic expressions in socioscientific group-discussions.

In a number of studies, individual students' argumentation ${ }^{5}$ have been investigated in terms of how they justify and elaborate their statements (cf. Erduran, et al., 2004; Kolst $\varnothing, 2001$ b, 2006; von Aufschnaiter, Erduran, Osborne, \& Simon, 2008; Wu \& Tsai, 2007; Nielsen, 2011; see also the recent review of Bravo \& Jiménez-Aleixandre, 2011). Occasionally, investigations are accomplished by estimating individual students' argumentative progress through preand post-tests in connection with a SSIintervention (Lewis \& Leach, 2006; Lundegård \& Wickman, 2007; Zohar \& Nemet, 2002). Another form for data collection is interviews; either with single students (Kolst $\varnothing, 2001 b$; Sadler, Chambers, \& Zeidler, 2004) or in small groups (Lewis \& Leach, 2006). Wu and Tsai (2007) have used open-ended questionnaires for collecting individuals' argumentation, and Kolstø et al. (2006) have used students' written texts.

If one is interested in the collective meanings presented in group conversations, we believe that individual approaches, as well as interview-designs, would give a too restricted view. However, there are methodological exceptions where scholars apply group-assessments for investigating argumentative quality when accomplishing SSI. One is the analysis model used by Zohar and Nemet (2002), which allowed them to discern the collectively expressed conclusions, justifications, concessions and oppositions in students' conversations. However, they do not elaborate on what was said in terms of moral and critical views. In Ratcliffe's study, group discussions were analysed in terms of the skills, knowledge and values students used for underpinning their 
decisions (Ratcliffe, 1997). Attention was also given to the substance of the utterances, and cognitive as well as affective criteria for decisions were discerned. Lundegård and Wickman (2009) studied students' groupdeliberating on a SSI concerning global food supply, where the conversation inevitably touched upon value issues such as human freedom, duty and solidarity. They discerned occasions where students create "new affiliations" (p. 446) when differences and conflicts occurred during the discourse. The studies by Ratcliffe (1997) and Lundegård and Wickman (2009) are two exceptions that account for the ethical, moral and aesthetical considerations students use for decisionmaking in group-settings, even though they do not delve deeply into the qualitative aspects of these arguments. Following our knowledgeinterest, a fuller and richer understanding could be an outcome if attention is paid also to the relative abundance and significant meaning of the utterances.

A framework often used in qualitative assessments of argumentation is TAP, Toulmin's Argument Pattern (Toulmin, 1958/2003), where the content is divided into rhetorical devices like data, claims, warrants, backings and rebuttals. However, since we in line with Zeidler et al. (2003) advocate "deliberative and dialogical interactions" ( $p$. 106) and coordinated reasoning (p. 100), the TAP-model is still impaired. One of the shortcomings is that even if TAP focuses on the rational grading of the students' individual argumentation patterns, it does not meet our needs considering how individuals interact and develop their socioscientific reasoning through collective meaning-making. We also believe that analysing quality dimensions of dialogic reasoning is not just about monitoring whether science undertaken in accordance with accepted knowledge claims and canonical science. Attention should also be paid to the intrinsic intentions, opinions and values expressed in the conversations. One reason for this is that individual values and social considerations seem to dominate over scientific evidence and concepts in students' argumentations (Ekborg, 2005; Fleming, 1986; Grace \& Ratcliffe, 2002; Kolst $\varnothing, 2006$; Sadler \& Donnelly, 2006; Sadler \& Zeidler,
2004). With the exception of Grace and Ratcliffe's study (2002), these reports deal with students' reasoning in interview situations where they were questioned and more or less explicitly asked to develop and justify their positions. It is therefore considered significant to explore how these aspects are expressed and responded to in "naturalistic" peer-group settings.

We also see the need for analyses that take several aspects of the multifaceted concept "critical thinking" into account. We believe that research concerning critical thinking in science education has been restricted to encompass only a few of Ennis' (1993) and Winch's (2006) list of critical thinking-related abilities and dispositions. We align with scholars who maintain that critical thinking is not just about being able to seek evidence and use rational criteria for decisions. It also entails other components of emancipation and democracy, such as being able to scrutinise unfair conditions in order to "empower students to understand the society around them and their own capacity to transform it" (Erduran \& Jiménez-Aleixandre, 2007, p. 8).

To conclude, previous research has contributed extensive knowledge about the relationship between language and scientific learning. It has also elucidated a number of important factors relating to the quality of students' argumentation capacity and pointed out that if science education for citizenship is to be taken seriously, it needs to go beyond the limited interpretation of democracy goals in terms of simply mastering subject-specific content and accomplishing scientific inquiries. It should also provide opportunities for students to actively engage in dialogues that entails and demands qualities such as consideration, moral reasoning and critical thinking in relation to social agreements and fundamental values. There is a growing imperative that such proficiencies could be practised through conversations concerning SSI. However, in line with Zeidler et al. (2003) and Sadler et al. (2007), we draw attention to the need for formative evaluations of the SSI-processes in order to understand to what extent this is done. Ideally, these methodological applications should reveal 
students' argumentative patterns and considerations when dealing with the entwined domains of contemporary science, values and norms. Such clarifications would point out strengths and weaknesses in students' group-conversations and provide further guidance for an integrative understanding of content knowledge and democracy in science education. What we hope for is that the analysis instrument presented here will contribute with knowledge considering how to accomplish this.

\section{Theoretical Foundation of DEQUAL}

The theoretical foundation of the tool is a communicative philosophical perspective on education, democracy and meaning-making primarily based on the works of John Dewey and Jürgen Habermas. One could argue that both Dewey and Habermas formulate and uphold a theory of communication with a unifying emphasis on the significance of intersubjectivity for democratic growth (Biesta, 1994). This interconnectedness is also pointed out by Englund (2006), and Englund, Öhman and Östman (2008).

In our research, Habermas and Dewey are united for pragmatic reasons. Dewey's comprehensive perceptions of democracy, communication and meaning-making provide the over-arching philosophical framework, while Habermas embodies and formalises communicative conceptions in terms of deliberative conversations, which we regard as a way of perceiving communication that can be refined into methodological applications for investigating conversations empirically.

\section{Deweyan Influences}

John Dewey highlights the fundamental significance of language and mutual communication for the individual's functional coordination with the social environment. $\mathrm{He}$ maintains that language is "the tool of tools" (Dewey, 1929/1958, p.168), enabling people's communicative ambitions which are based on an expressed striving for participation and fellowship. When communicating, individuals coordinate their activities and create meaning, which indicates that meaning-making is regarded as a social process (see Garrison, 1995; Öhman \& Östman, 2007).
Meaning is thus framed and reframed in linguistic actions in which people's experiences are encountered, addressed, tested and developed. Individual thoughts and desires are seen as "a preliminary, tentative and inchoate mode of action" that has to be challenged in communicative processes where "the meanings animating behaviour" are created (Dewey, 1929/1958, p. 221). Furthermore, by stating that "conflict is the gadfly of thought" (Dewey, 1922/2007, p. 300), Dewey pinpoints a consistently advocated viewpoint that the elaboration and development of human conduct benefits from taking diverging opinions into consideration (cf. Dewey, 1922/2007, 1929/1958). In the tension field between contrasting voices, new meanings in terms of changes of action appear.

The new meanings can be cognitive in nature in terms of (factual) knowledge formation. They may also involve new ways of looking at individual and social principles and values. Whatever the case, changes in the view of the world occur, and according to pragmatic philosophy, the changes can only be confirmed if and when they are exposed to the world as actions. In our analysis tool (Table 2), attention is paid to observed (articulated) new meanings as a specific category: "New possibilities". In a different context, this category might have been denominated "learning".

Dewey opposes systems of thought with dichotomising ontological presumptions where, for example, natural sciences and philosophical values are considered as separate entities:

The view which isolates knowledge, contemplation, liking, interest, value, or whatever from action is itself a survival of the notion that there are things which can exist and be known apart from active connection with other things (Dewey, 1929/1958, p. 435).

Consequently, he maintains that education should not be restricted to the reproduction and transmission of scientific facts, since "as soon as science is actually used, as soon as action based upon it occurs, then values, consequences enter in" (Dewey \& Childs, 1933/1986, p. 78). Based on these 
Deweyan viewpoints, scholars such as Webster $^{6}$ (2008) stress the need for integrating critical, moral and ethical dimensions in science education. Webster writes that by allowing such experiences, educators offer "the potential to illuminate the meanings and purposes of the very lives of our students" ( $p$. 905).

Ethical and moral reasoning are frequently recurring themes in Dewey's writings - thoughts that are thoroughly dealt with in an extensive volume by Pappas (2008), where the latter points out that a distinctive trait in Dewey's ethics is the situational dimension of moral meaningmaking:

[A]ny adequate examination of Dewey's ethical vision needs to begin and take as central the notion of a situation [...]. Moral experience is experienced as something that is neither subjective nor merely inter-subjective. We begin where we are, in a situation as participants, rather than as inhabitants of a culture, conceptual scheme, or our society's norms [...]. The categories and elements that are part of moral experience (such as character, conduct, principles, relationships, and habits) are features or traits of lived situations, not antecedents to them (Pappas, 2008, p. 42).

For our purpose we confine ourselves to making a mental note of Dewey's view that science "in action" inevitably entails ethical and moral dimensions which, when revealed and scrutinised, develop into elaborated moral experiences that "will illuminate and guide the activities of men" (Dewey, 1922/2007, p. 296). For this reason, our DEQUAL-tool also pays attention to ethical and moral reasoning.

When Dewey describes his conception of democracy he points out that by offering and achieving participation, schools lay the foundation for collective actions and social participation in the future (Dewey, 1916/1999). He highlights the role of school as a democratic and communicative arena in which participation, community and meaning can be created. For Dewey, "democracy" is not just an expression of a form of government in which individuals have the right to participate in decision-making, but is to be regarded as "a mode of associated living, a conjoint communicated experience" (Dewey, 1916/1999, p. 87) in which citizens develop and manage shared values through deliberative considerations of different approaches and perspectives (Dewey, 1927/1988). In this context, Dewey connects democracy with science by highlighting the benefits of applying a scientific approach for investigating and examining alternatives and that rational scientific logic is also suitable for scrutinising value questions, since these also need to be exposed to revision and intelligent judgements (Dewey, 1916/1999, see also Hickman, 2009).

For Dewey, the overarching goal in a democratic culture is to provide for people to live meaningful lives, made possible if citizens are given opportunities to practise and develop social intelligence and individuality in order to partake in the democratic society with consideration but without surrendering to conformity. His democratic intentions could be seen in terms of a reciprocal give-and-take between the individual and the community, where well-equipped and considerate citizens scrutinise the societal reality in search for new ideals "directed to consummatory ends", using Alexander's (1994) Deweyan-influenced wording (p. 78).

According to Dewey, the democratic life form is safeguarded and practised in communicative processes between different people expressing diverse ideas (Dewey, $1916 / 1999,1927 / 1988)$. This conviction is shared by Jürgen Habermas, who occasionally refers to Dewey when elaborating on it in his comprehensive "Theory of Communicative Action" (Habermas, 1984, 1987). Even though Habermas does not add the same philosophical force in educational questions, he shares Dewey's conviction about communication's significance for reciprocity and democracy.

\section{Habermas' Contributions}

In this article, we do not intend to go too deeply into Habermas' extensive and complex social theory about human interaction and social order (Habermas, 1984, 1987), nor do we take up any position on the philosophical 
truth of his reasoning. Our position is rather a belief that with the aid of Habermas, we can accomplish a deeper understanding about the qualitative and content-specific dimensions of the SSI-conversations.

Habermas maintains that people's points of view are formed and changed in encounters with genuine, truthful and accurate arguments in deliberative conversations, where account is taken of all those affected and where the objective is to reach a decision that everyone can accept (Habermas, 1984, 1996). He claims that in order to reach valid settlements, an ideal, undistorted deliberative conversation needs to live up to certain principles. It must be open (inclusive), symmetrical, impartial, free from oppression and constraint and critical in relation to "taken-for-granted" assumptions (Habermas, 1990); as well as "careful, serious and reasoned" as Fearon (1998) states (p. 63). One is expected to take other people's views into account and consider those who are affected by the decisions made, even if others are physically-, geographically- or time-removed. In other words, one should be able to make others "imaginatively present" (Goodin, 2003, pp. 63-64). The performance levels are thus higher than those for discussions and debates. The expectations are that weak arguments, prejudices and misunderstandings can be "washed away" during deliberation, and that the participants, for example students cooperating on SSI, can agree on a decision that matches and addresses the problem.
Over time, his philosophy of language has been complemented and developed in terms of moral philosophy. Habermas believes that human reasoning and conduct can be vindicated from three different action rationalities: ethical, moral or pragmatic. When it comes to communicative encounters comprising pragmatic, ethical or moral reasoning, these are legitimised in different ways. While pragmatic arguments could be validated according to effective and rational demands in order to reach specific goals, ethical reasoning concerns what kind of life one would like to live, and whom one is, and would like to be in order to live a good life together with others (Habermas, 1993). Such issues are pronouncedly influenced by individual and cultural values, emotions and particular interests. This means that even though agreements on ethical issues can be reached in such contexts, general validity of these ethical standards fails (Habermas, 1993). A group of students discussing how to reduce the effects of global warming could for example agree on how to live presupposing this phenomenon is a hoax, even though this normative statement lacks validity outside the group. The most extensive validity claims are imposed on moral reasoning. The accuracy of moral standards must be tested and determined in communicative actions, and Habermas provides an argumentative rule which means that all those concerned should accept the consequences that follow. It should thus be elevated to a general maxim that everyone can accept. With this as a guideline it is possible to go beyond egocentric and narrow socio-centric preferences and values and instead think in terms of our duty to others. Habermas states that this principle is essential for deliberations on moral issues (Eriksen \& Weigård, 2003; Habermas, 1993,1996).

Eriksen and Weigård (2003, p. 76) summarise Habermas' apprehensions considering rationalities behind human reasoning, and further integrate them with his perceptions considering the three worlds (see above). Their interpretation is that according to Habermas, a conversation content focusing on revealing relevant facts and seeking theoretical knowledge about what is 
Interest a tool for investigating deliberative qualities

considered as scientifically true relates to the objective world. Since such reasoning is not regarded as action-oriented, Eriksen and Weigård (2003) believe it falls outside of the Habermasian perception considering ethical, moral and pragmatic rationality. In DEQUAL, this view is put into practise. However, in accordance with our understanding of Habermas' moral philosophy (Habermas, 1993); pragmatic, ethical and moral reasoning all relate to the social world of common understanding concerning principles of action where also subjective opinions about ethics and morals are given space.

With his philosophical images concerning how mutual understanding can be achieved and agreements can be vindicated, Habermas emphasises and extends the conception of the power of linguistic communication. advocating educational processes "where individuals bring different perspectives to ongoing communication" (Englund, 2000, p. 305). He sees activities, where deliberative capabilities are developed, as one way to realize a democratic conception of education implying a communicative rationality. Inspired by Dewey, but mainly based on the ideas of Jürgen Habermas, Englund (2006) suggests five guidelines in order to concretise the character of deliberative conversations in school (see also Englund, Öhman \& Östman, 2008). These guidelines are presented in Table 1 below.

If idealistic guidelines like these are put into practice, they become subjects for empirical scrutiny. In such case, there must be methods for investigating the democratic outcome of classroom conversations, for

Table 1. Guidelines for deliberative communication in school (from Englund, 2006, p. 512)

Deliberative communication implies communication in which:

(a) different views are confronted with one another and arguments for these different views are given time and space to be articulated and presented;

(b) there is tolerance and respect for the concrete other and participants learn to listen to the other people's arguments;

(c) elements of collective will-formation are present, i.e. an endeavour to reach consensus or at least temporary agreements or to draw attention to differences;

(d) authorities or traditional views (represented, for example, by parents and tradition) can be questioned, and there are opportunities to challenge one's own tradition; and

(e) there is scope for students to communicate and deliberate without teacher control, i.e. for argumentative discussions between students with the aim of solving problems or shedding light on them from different points of view.

\section{The Analysis Tool DEQUAL}

If one accepts Dewey's and Habermas' interconnected perceptions where democracy and meaning-making are interpreted in intersubjective, communicative and deliberative terms, students' deliberations on SSI constitute science-teaching situations where these philosophical ideals could be implemented and assessed in practice. In the rhetoric concerning empowerment and active citizenship, several authors claim that deliberative conversations have the potential of serving as vehicles for the development of democratic skills and virtues (cf. Carleheden, 2006; Fearon, 1998; Gutmann, 1999). The Swedish educationalist Tomas Englund (2000) shares this conviction and refers to John Dewey's pioneering work Democracy and Education (Dewey, 1916/1999) when example concerning SSI, seen in deliberative terms. In order to provide methodological knowledge in this field, we took on the assignment to present a tool for such investigations.

In the construction of the DEQUAL-tool we departed from Englund's procedural model (Table 1) for how deliberative conversations could be performed. However, supplements were needed since it inadequately considered the full spectrum of dimensions we wished to cover. Since one always talks about something, we believe that the content-dimension of the conversations also needs attention. In line with Dewey (1916/1999, ch. 13-14) we find it impractical to separate method and subject matter. Thus, we maintain that in order to create meaning, the "how" and the "what" must be regarded as 
an indivisible whole. Consequently, an analysis tool for investigations of groupconversations on SSI which considers formal as well as content-related aspects is suggested here.

DEQUAL took shape through a thorough and consecutive, abductive process in which our theoretical suppositions concerning democracy and intersubjective communication alternated with empirical data. The latter constituted of 25 recorded and transcribed group-conversations, in which 1617 year old students in upper-secondary school communicated on a socioscientific issue without the presence of any teachers. The recordings were made in order to catch various conversations on topics concerning the greenhouse effect. With the theoretical backings presented above, there was a need for a tool taking these into account. DEQUAL emanated from a desire to meet this need. On reading through the empirical material, common patterns emerged that led to extensions and subsequent modifications of the tool. For example, one finding was that the group members occasionally helped each other with the missing justifications, which accentuated the need to go beyond the

Table 2. The DEQUAL-analysis tool, aimed for investigating deliberative qualities in SSIconversations

\begin{tabular}{|c|c|c|}
\hline Category & $\begin{array}{l}\text { Sub- } \\
\text { category }\end{array}$ & Description \\
\hline \multirow[t]{4}{*}{ R. Reasoning type } & $\mathrm{T}$ & $\begin{array}{l}\text { Theoretical. The conversation concerns facts, concepts, } \\
\text { "truths" (the objective world). }\end{array}$ \\
\hline & $\mathrm{P}$ & $\begin{array}{l}\text { Pragmatic. The reasoning contains individual or shared } \\
\text { perceptions of practical, useful, conventional conduct. }\end{array}$ \\
\hline & $\mathrm{E}$ & $\begin{array}{l}\text { Ethical. Individual or shared perceptions and beliefs } \\
\text { considering feasible life and good practise. Limited ("local") } \\
\text { socio-centric view, where considerations are restricted to } \\
\text { one's friends, "us youngsters', the municipality, familiar } \\
\text { surroundings. }\end{array}$ \\
\hline & M & $\begin{array}{l}\text { Moral. Mutual agreements on one's obligations to one another } \\
\text { in terms of right, just, honest actions. Expanded socio-centric } \\
\text { view, where considerations cross geographical or generational } \\
\text { boundaries. }\end{array}$ \\
\hline \multirow{2}{*}{$\begin{array}{l}\text { A. Argument } \\
\text { completeness }\end{array}$} & 1. & Incomplete argument (claim without justification). \\
\hline & 2. & Complete argument (claim + justification) \\
\hline \multirow[t]{2}{*}{ D. Dimensions } & $\begin{array}{l}1 . \\
2 .\end{array}$ & $\begin{array}{l}\text { Restricted. Either lack of response or monosyllabic support. } \\
\text { One-dimensional. Supportive or supplementary sentences in } \\
\text { relation to a presented claim or argument. }\end{array}$ \\
\hline & 3. & $\begin{array}{l}\text { Multi-dimensional. Episode deliberation comprises different } \\
\text { views and arguments. }\end{array}$ \\
\hline \multirow[t]{4}{*}{ Q. Questioning } & 1. & Non-existent. \\
\hline & 2. & $\begin{array}{l}\text { Inquiring. Questions in order to find out something one does } \\
\text { not know. }\end{array}$ \\
\hline & 3. & $\begin{array}{l}\text { Critical. Reflective thinking focused on deciding what to } \\
\text { believe or do. }\end{array}$ \\
\hline & & $\begin{array}{l}\text { a) Facts, concepts, "truths" (the objective world). } \\
\text { b) Behaviour, values, norms, authorities, tradition. }\end{array}$ \\
\hline \multirow[t]{2}{*}{ N. New possibilities } & 1. & No notable changes due to mutual influence. \\
\hline & 2. & $\begin{array}{l}\text { Changes (newfound meanings, pronounced new experiences). } \\
\text { a) Facts, concepts, "truths" (the objective world). } \\
\text { b) Behaviour, values, norms, authorities, tradition. }\end{array}$ \\
\hline \multirow[t]{2}{*}{$\begin{array}{l}\text { M. Mutuality and } \\
\text { respect }\end{array}$} & 1. & $\begin{array}{l}\text { Deficiencies in interpersonal tolerance and respect. } \\
\text { a) Group members, i.e. conversation peers. } \\
\text { b) Others. }\end{array}$ \\
\hline & 2. & Equal, respectful and tolerant reception of others. \\
\hline
\end{tabular}


Interest a tool for investigating deliberative qualities

individual perspective in order to capture the presence and quality of the collaboratively expressed arguments. Another noticeable trend, not prognosticated on theoretical grounds, was that the claims often took the form of indisputable and unsupported assertions that were neither contradicted nor elaborated on. The observations led to the construction of the DEQUAL-category" Argument completeness" (A) and refinement of the sub-categories in "Dimensions" (D). The idea is that an analysis process begins by dividing the conversation into episode themes, where each theme consists of a distinct aspect of content, opinion or dimension, i.e. a new turn compared to the previous utterance. Thus, in line with Deweyan thoughts, the episode mirrors the cooperative meaning-making over a specific content. The conversation content of each episode theme is then qualitatively classified according to the categories and subcategories in DEQUAL (Table 2). The first category, reasoning type (R) embraces the rationality behind the episode conversation, where the sub-categories reflect Habermas' ideas about deliberative conversations (Habermas, 1984) and the rational grounds for reasoning (Habermas, 1993). An episode content oriented towards an objective world of (scientific) facts is sub-categorised as theoretical (T), while one referring to affections and beliefs, social agreements and common standards is sub-categorised as either pragmatic, ethical or moral according to the apprehensions about rationality (ibid.).

The second category regards "argument completeness" (A), which connects to Englund's point a in Table 1, saying that arguments for different views should be given time and space in deliberative conversations. Arguments are here seen as assertions/claims followed by justifications (Kolstø \& Ratcliffe, 2007; Toulmin, 1958/2003; Zohar \& Nemet, 2002). The argumentation is accordingly classified as incomplete (A1) or complete (A2) depending on whether justifications are present or not. As for subsequent categories in the tool, a higher denoted figure is indicative of qualitative progression. Since each episode theme allows for several student voices, a total assessment of all the utterances in an episode is possible; something that differentiates this instrument from others which focus on individual students' reasoning ability.

The quality category $\mathrm{D}$ deals with the same point (a) in Table 1 in the sense that it mirrors the extent to which episodic statements comply with the request that multiple views are reflected upon. The episode categorisation will be D3 if it does. Otherwise it will be D2 if the response from others is supportive or supplementary in relation to a posed claim, or D1 if the response is lacking or restricted to monosyllabic vocalizations.

The analytical category "Questioning" (Q) makes it possible to spot any questions and contestations that may occur. This category reflects the formal guideline described in Englund's point $d$ in Table 1. The inquiring mode of questioning $(\mathrm{Q} 2)$ is about discovering something one does not know. Such questions are inclined to result in notable changes in terms of new meaningmaking or "learning". Since deliberative conversations are assumed to allow free scope for critical thinking (see point $\mathrm{d}$ in Table 1), the tool also allows us to discern the occurrence of critical dimensions and whether the questioning refers to the objective domain of theoretical statements or the social/subjective world of beliefs, values or tradition, based on Habermas' philosophical perceptions. The reason for merging social and subjective aspects is the revealed difficulty distinguishing them from each other when reviewing the empirical material. An utterance such as: "you should not drive so much" exemplifies this problem. Since it is not possible to make a qualitative distinction between the two types of questioning, these are sub-categorised with letters $(a, b)$, instead of numbers.

The category "New possibilities" $(\mathrm{N})$ is introduced in order to present a clearer view of the nature of occurring meaning-making events. Here, the presence of changes in the form of new meanings arising from mutual influences is recorded. The N-category is a tangible application of John Dewey's thoughts considering common understanding and meaning-making. 
The M-category, mutuality and respect, makes is possible to specify if those present and non-present are treated with tolerance, respect and equity in the conversation. It connects to point b in Englund's model (Table 1). Disparaging utterances are classified as either M1a or M1b, depending on whether the disrespected other is a conversation partner or someone external, talked about. Episodes without verbal maltreatment of others are regarded as respectful (M2).

As elucidated, Dewey's as well as Habermas' thoughts are implemented in the tool, where Englund's guidelines presented in Table 1 facilitated the interpretation of deliberative conversations in school. The entire collection of guidelines in Table 1 was, however, not operationalised. Since the analytical units represent the separate episodes, estimating the endeavour to reach consensus (point $\mathrm{c}$ ) from fragments of a conversation is less meaningful. Instead, this dimension can be dealt with as a comprehensive post-assessment of the entire conversation. Also, the aspect that peers should have the opportunity to communicate with each other without teacher control (point e in Table 1) must be addressed outside the framework of the tool. In the following sequence, examples from a DEQUALanalysis are presented.

\section{Illustration}

A conversation between upper secondarystudents John, Peter and Carl on the Technology Program is used in order to demonstrate the interpretative and operational steps of DEQUAL. The school represents a mix of ethnic groups and socioeconomic backgrounds common in Swedish upper secondary schools. In this particular program a majority of the students are boys. The excerpts are chosen from comprehensive empirical material covering 54 youngsters' partaking in 25 group-conversations within the framework of "Science Studies A", a 50hour compulsory subject for all Swedish students at upper secondary school. This course focuses mainly on environmental issues, but also touches on ecology and the use of energy and natural resources. One of the goals of the course is that pupils should be able to distinguish between statements based on facts and value judgments. They are also expected to learn about the conversion of energy, different energy forms and energy quality, and be able to participate in discussions concerning environmental and lifestyle problems and consider how they might influence the outcomes.

The socioscientific task, which was constructed by the first author, was developed around the main question of whether it was better to live in an urban area or in the countryside, given that each case has some bearing on climate change. The fundamental ideas were that the scenario would allow for ethical and moral reflection on lifestyle, social influence and solidarity, and that this could be perceived as interesting and relevant, given the students' reality. The lesson began with the first author describing the lesson outline and that the task was about using scientific knowledge to discuss and take a position in social issues where it can be difficult to determine what really is right and wrong. The current topic of conversation as well as the instructions for the task were recorded in a written document which was distributed to each student. The content of the document was also explained to the students, and it was underlined that it was important to take everybodys opinion into account and that they would seek to highlight as many aspects and arguments as possible concerning the discussed issues. Everyone was asked to think about the socioscientific issues presented in the document for a few minutes and then to write their name and their opinion on the matter in a distributed note sheet. Before the discussion began the class was randomly divided into groups of 3-5 students.

In the following we use excerpts from three episodes of this conversation. The excerpts have been chosen because they are representative of the conversation that took place in this class in general, they have an illustrative richness and many of the classifications of the DEQUAL-tool are represented. In total it covers seven minutes of "effective" talk, in which nine different episode themes concerning the socioscientific topic were discerned.

Episode 1. It's better to live in town ( $R P, R M$, $A 2, D 2, Q 1, N 1, M 2$ ). 
JOHN: Okay, what do you think? Should you live in town or out in the countryside? I'd say it's better to live in town.

PETER: Town.

CARL: (in a delegating tone) OK, town is best. That's due to the greenhouse effect, why's that?

PETER: Because then you can sort of cycle to everything.

JOHN: Yes, that's what I mean, you know. If you have to go to the shop, sort of, you cycle there and buy something. If you live out in the country then you have to sort of drive there for about half an hour, and release masses of exhaust fumes and crap into the atmosphere.

In this first episode the students immediately accept the underlying values of the socio-scientific task, namely that we should all try to reduce the risks of global warming. In the conversation the students create a causal link between driving and greenhouse-gases and conclude that it is better to live in town than in the countryside because it is easier to cycle to where you want to go. This signifies a pragmatic rationality (RP) about how to best reach the goal, i.e. to reduce global warming. The talk about cycling in order to avoid the "fumes and crap" released when driving can also be seen as in moral terms (RM). This is an example of students helping each other to form a complete argument (A2). John formulates the claim, Peter fills in with a justification and John elaborates on it. In the episode, only one dimension (you don't have to drive that much) of the statement (that it is better to live in town) is presented (D2). No questioning and no new possibilities are seen $(\mathrm{Q} 1, \mathrm{~N} 1)$, and the episode conversation is considered as mutual and respectful (M2).

After John's utterance about 'fumes and crap in the atmosphere" (see episode 1, above), these students start to discuss whether it could be better to live in the countryside since you could easier use firewood for heating. They turn into debating whether such heating leads to more or less carbon dioxide in the atmosphere, compared to using fossil fuels. This part of the conversation, considered as episode 2, comes to an end when John says 'I've got that district heating", which leads the conversation into the following episode:
Episode 3. Environmentally friendly energy systems (RT, RM, A1, D3, Q2, Q3b, N2a, M2).

JOHN: I've got that district heating.

CARL: Oh... cool.

PETER: And we've got this air-thing that blows in from outside and stuff.

JOHN: $A h$.

PETER:That must be damned environmentally friendly.

JOHN: Yes, it is.

PETER: There you see, thanks!

JOHN: So Carl lives there... What does he

do? They use pellets for heating...Pellets!

CARL: So what. Is that wrong?

PETER: Can you, can you heat a house with pellets?

CARL: Mm, in a (xxx) (inaudible).

PETER: No but... Pellets aren't they like those little white things that look like candle wax that you light and throw into the fire so it starts to burn better.

CARL: Oh no.

PETER: What the hell is a pellet?

CARL: Pellets are kind of, bits of wood

pressed together into little pieces...

Episode 3 contains a discussion about how environmentally friendly various types of energy systems are; a content that relates to the objective world (RT). However, one can also spot a moral rationality (RM) entailed in Carl's unanswered question "Is that wrong?" In the reasoning, which partly resembles a competition between the students, it is claimed that district heating is "cool" and that heat exchangers are environmentally friendly. These statements are not justified or explained (A1), however. Several dimensions of the episode theme are presented (D3). Peter is not certain about what pellets are, so he asks questions about this (Q2). When wondering about whether to defend pellet-heating, Carl questions values and norms for good environmental conduct which additionally renders a mark also in the Q3b-category. In this episode, Peter's former experience and understanding about pellets is widened (N2a). In accordance with the previous episode, this conversation is free from disparaging utterances (M2).

Episode 9. Unrealistic task (RP, A2, D3, $Q 1$, Q3b, N1, M2).

CARL: Honestly, how many think when they want to move: Ah, let's see, because of 
the greenhouse effect, shall we move out into the countryside or to the town?

PETER: Except this assignment is not as stupid as the technical one.

CARL: Nah.

PETER: That's really weird!

JOHN: I hate it! We don't learn anything from that at all.

This extract shows a different pattern of reasoning in the sense that the students do not find the socioscientific scenario realistic. They question the relevance of the scenario on pragmatic ground (RP), which in turn means that they critically question the norms and values embedded in the task (Q3b). Carl justifies the claim that the task is unrealistic by ironically questioning who would use the greenhouse effect as an argument for settlement (A2); and the claim is supported by differentiating comments from Peter (D3) saying that the task is not "as stupid as the technical assignment". Carl's questioning concerns behaviour and values as well as the teacher's choice of conversation task but there is no attempt to see this utterance from different perspectives. The episode is therefore be categorised as a critical questioning of values (Q3b) although it in a certain sense also qualifies as (Q1), since questioning of this critical claim is nonexistent. There are no notable changes of experiences (N1), and others are treated respectfully (M2).

The performed DEQUAL-analyses can be compiled quantitatively. In order to show the full width of the specific dialogue between John, Carl and Peter, their conversation profile containing nine episode themes is presented in Table 3.

Various dialogues give rise to specific conversation profiles where, when compared, differences and common features emerge. Due to contextual conditions, such as a participant's individuality and the dynamics in the group, the talk takes different turns. However, DEQUAL makes it possible to study the relative distribution between valuerelated and theoretical (scientific) argumentation. Such overviews allow for comparisons and revelations of occurring weak spots in the deliberations. For example, an overview of the communication between Peter, Carl and John (Table 3) shows that emphasis is put on factual, theoretical issues connected with the emission of greenhouse

Table 3. The DEQUAL-profile of a socioscientific conversation between John, Carl and Peter concerning the greenhouse effect and living in a certain place.

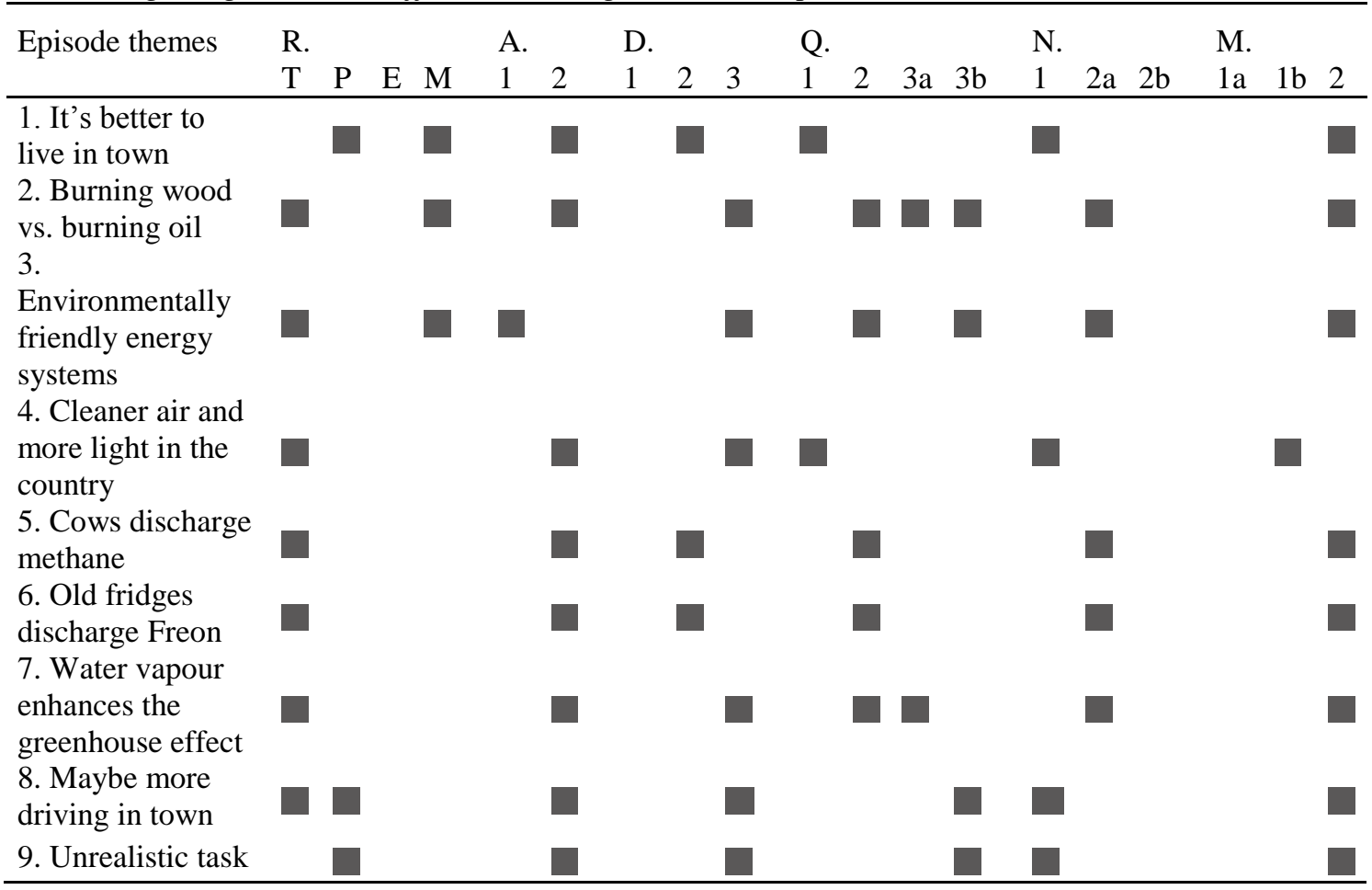


gases, while ethical and moral reasoning is less frequent. In most of the cases the students are able to elaborate complete arguments (A2), often from more than one viewpoint (D3). There is also a relatively high degree of inquiring questioning in order to "get things right" (Q2). Furthermore, critical questioning is relatively frequent too (Q3a, Q3b). These result in "aha-moments" and notable changes of meaning; in this conversation mainly considering the objective world (N2a). The mark in the M1b-column in episode 4 signifies a student's claim that people living in the country are "goddamn inbreeding". This utterance is left without comments.

\section{Discussion and Implications}

With the DEQUAL-tool, founded on Dewey's and Habermas' conjoined philosophical apprehensions considering democracy, education and communication, it is possible to:

- Distinguish what the participants choose to talk about and on what grounds they reason.

- Review whether possessed claims are justified and if different views and arguments are presented.

- Establish if questioning occurs in the conversation; and if so, whether this is inquiring or critical.

- Discern pronounced new experiences in terms of newfound meanings in the dialogue.

- Recognise occasions of disparaging treatment of others.

As we see it, the tool facilitates developed understanding on formal and substantial qualities of group conversations on socioscientific issues (SSI) where democratic ambitions are prevailed. This means that SSI represents a way of teaching by which democracy can be practised and promoted. In this sense, the analysis tool DEQUAL offer guidance for teachers and researchers concerning how and on what basis students communicate and what they choose to highlight in their discussions. This information can be used in order to elucidate the need for further efforts in order to develop not only argumentation quality, but also ethical and moral concern. Furthermore, DEQUAL can provide detailed information about the profile of the qualities of students' discussions (see example in table 3 and the discussion above) which makes it possible to be more specific about interventions to improve the discussions.

There are of course a number of limitations both concerning the use of socioscientific discussions and the DEQUALtool. The use of such discussions and the tool is probably most suitable for educational systems where democracy and intersubjectivity is practiced. But even in such systems students are constantly assessed by teachers, which means that they might prefer coming up with answers that they feel are expected and "right", rather than ones that would be challenging (see Öhman \& Öhman, 2012). In addition, the social cohesiveness that exists among young people is generally more important than examining the diversity of opinions and ideological conflicts. We have also found that it is important to carefully select issues that really concerns the students and also where there supposively is a diversity of opinions on this topic among them (and not only select issues that are contested in the political debate in general).

Another problem is the deliberative ideal that the teacher should be absent in the discussion. Previous studies have shown the importance of the teacher supporting the quality and the democratic aspects of the discussions (Rudsberg \& Öhman, 2010). If a more diverse discussion is intended it is often necessary for the teacher to take an active part in the students' discussions in order to challenge the common view and allow for alternative possibilities and views. An obvious limitation of DEQUAL is that it does not evaluate the role of the teacher.

According to the ideas of deliberative discourse, permitting social contexts and convictions of equality are crucial. This has been seen as a rather idealistic view, since in reality discourses are often distorted by unjust power relations and group-polarisations that force the process on non-democratic premises (Sunstein, 2003; Young, 2003). Moreover, a deliberative conversation is a relatively controlled procedure, which may be perceived as questionable on the basis of democratic claims. Those who participate are, for 
example, expected to reach consensus. This has been criticized as too compelling, since, as Shapiro (2003) writes, "people may not, in any case, want to settle all their disagreements. They may perceive consensus as oppressive, and they may take pleasure in differentiating themselves from one another" (p. 124). Likewise, the teacher's relatively modest role in deliberative conversations can be questioned, since students' conversations may benefit from teachers acting as instructors, content knowledge experts, counselors and/or facilitators ${ }^{7}$.

We take the critique seriously and we therefore do not imply that the characteristics for deliberative conversations are essential for the implementation of good conversations about SSI. The main reason for referring to deliberative ideas when constructing DEQUAL was that they offer a framework for investigating socioscientific conversations with democratic aspirations as points of departure. However, the analysis tool does not deal with all aspects of the deliberative communication's ideal nature since it does not encompass the endeavour to reach consensus or agreements. We believe that the agreementaspect can be highlighted in the instructions for socioscientific conversations, where it is also made clear that the intention is not to win a debate but to hold respectful conversations about alternative views in which all voices can be heard. Furthermore, for obvious reasons, the instrument cannot be used for testing the extent to which students are need more testing. For example it would be valuable to test it in different educational contexts, in various group constellations, with diverse tasks and dissimilar preparation of the students, etc. We therefore look forward to receiving reactions concerning the applicability of the tool and welcome suggestions for further modifications.

Furthermore, even though DEQUAL is primarily thought of as a research tool for elucidating investigations in the SSI-domain, we envision enlarged fields of its application as a pedagogical instrument usable for staging teaching efforts, where we believe DEQUAL can serve as thinking tool, providing useful information when planning, implementing and formatively assessing socioscientific conversations. It can also be useful for formative assessments of students' scientific and democratic progress. These potentials need to be investigated further.

Berkowitz and Simmons (2003) write that "(a)s educators, especially as science educators, our ultimate task is to not to teach science, but to teach human beings" (p. 135). In line with Dewey, we do not, however, regard the two as dualistically separated. Instead, we take the view that they constitute the conjugated task of education. An apprehension on our part is that we have generally focussed on examining the scientific dimension of this mission ${ }^{8}$; therefore we believe that more knowledge considering the "humanistic" part of the assignment is required. Thus, in this contribution, the democratic dimension of the teaching assignment has been brought to the fore, and a tool for investigating socioscientific issues which draws attention to and captures various democratic dimensions has been presented. As we see it, in deliberative as well as socioscientific conversations, one has an opportunity to present one's opinions and listen to those of others. Through this communication, statements, demands and positions can be justified and questioned. In addition, it is hoped that the conversations result in expanded intellectual and moral reasoning. Our desire is that since DEQUAL pays attention to these traits, it may contribute to reconsiderations in order to provide a science education that comprehensively and integratively encompasses and accentuates 
content-specific knowledge and democratic growth.

\section{Notes}

${ }^{1}$ In this context, values are seen as "those ideas a person appeals to as criteria or warrants when judging the desirability of a certain action or conclusion" (Kolstø, 2006, p. 1693).

${ }^{2}$ Here we call attention to the outer similarity between DEQUAL and Lundegård and Wickman's DEQ (2007, 2009) where the latter stands for "deliberative educational questions", i.e. questions containing conflicts of interests, suitable for deliberations.

${ }^{3}$ Scientific literacy is defined by OECD as "the capacity to use scientific knowledge, to identify questions and to draw evidence-based conclusions in order to understand and help make decisions about the natural world and the changes made to it through human activity" (OECD, 2003, p. 133).

${ }^{4}$ STS stands for "Science and Technology in Society" or "Science, Technology and Society".

${ }^{5}$ The frequently occurring concepts of "argument" and "argumentation" should be understood as: assertions/claims followed by justifications (Kolst $\varnothing$ \& Ratcliffe, 2007; Toulmin, 1958/2003; Zohar \& Nemet, 2002), and a "dialogic process in which two or more people engage in debate of opposing claims" (Kuhn \& Udell, 2007, p. 90).

${ }^{6}$ For example in Lundegård and Wickman (2007, 2009), Wickman (2006) and Östman (2010), research based on Dewey's integrative view on philosophical values and science in educational practise is presented.

${ }^{7}$ In a later publication, Englund, Öhman and Östman (2008) clarify point e in Table 1 by emphasising the crucial role of the "absent" teacher for managing, planning and controlling students' deliberative communication even though not joining the actual conversation.

${ }^{8}$ However, a model for pedagogical assessments of students' democratic competence is presented by Gerrevall (2003).

\section{References}

Alexander, T. M. (1994). Educating the democratic heart: Pluralism, traditions and the humanities. Studies in Philosophy \& Education, 13(3-4), 243-260.

Bailin, S. (2002). Critical thinking and science education. Science \& Education, 11(4), 361-375.

Berkowitz, M. W., \& Simmons, P. (2003). Integrating science education and character education. In D. L. Zeidler (Ed.), The role of moral reasoning on socioscientific issues and discourse in science education (pp.117-138). Dordrecht: Kluwer Academic Press.

Biesta, G. J. J., \& Burbules, N. C. (2003). Pragmatism and educational research. Lanham, MD: Rowman \& Littlefield.

Biesta, G. J. J. (1994). Education as practical intersubjectivity: Towards a criticalpragmatic understanding of education. Educational Theory, 44(3), 299-318.

Bingle, W. H., \& Gaskell, P. J. (1994). Scientific literacy for decisionmaking and the social construction. Science Education, 78(2), 185-202.

Bravo, B. \& Jiménez-Aleixandre, M. P. (2011). A learning progression for using evidence in argumentation: an initial framework. Presentation on the European Science Education Research Association conference, September 5th-9th 2011, Lyon, France.

Carleheden, M. (2006). Towards democratic foundations: A Habermasian perspective on the politics of education. Journal of Curriculum Studies, 38(5), 521-544.

Dewey, J. (1916/1999). Democracy and education: An introduction to the philosophy of education. New York: Free Press.

Dewey, J. (1922/2007). Human nature and conduct: An introduction to social psychology. New York: Holt.

Dewey, J. (1927/1988). The public and its problems. In J.-A. Boydston (Ed.), John Dewey. The later works 1925-1953. Volume 2. (pp. 235-372). Carbondale, Illinois: Southern Illinois University Press.

Dewey, J. (1929/1958). Experience and nature. New York: Dover.

Dewey, J. (1938/1998). Experience and education (60th anniversary ed.). West Lafayette, Ind.: Kappa Delta Pi. 
Dewey, J., \& Childs, J. L. (1933/1986). The underlying philosophy of education. In J.A. Boydston (Ed.), John Dewey. The later works 1925-1953. Volume 8. (pp. 77-103). Carbondale, Illinois: Southern Illinois University Press.

Ekborg, M. (2005). Is heat generated from a crematorium an appropriate source for district heating? Student teachers reasoning about a complex environmental issue. Environmental Education Research, 11(5), 557-574.

Englund, T. (2000). Rethinking democracy and education: Towards an education of deliberative citizens. Journal of Curriculum Studies, 32(2), 305-313.

Englund, T. (2006). Deliberative communication: A pragmatist proposal. Journal of Curriculum Studies, 38(5), 503520.

Englund, T., Öhman, J., \& Östman, L. (2008). Deliberative communication for sustainability. In S. Gough \& A. Stables (Eds.), Sustainability and security within liberal societies. Learning to live with the future. New York: Routledge.

Ennis, R. H. (1993). Critical thinking assessment. Theory into Practice, 32(3), 179-186.

Erduran, S., \& Jiménez-Aleixandre, M. P. (2007). Argumentation in science education: Perspectives from classroombased research. Dordrecht: Springer.

Erduran, S., Simon, S., \& Osborne, J. (2004). TAP-ping into argumentation: Developments in the application of Toulmin's Argument Pattern for studying science discourse. Science Education, 88(6), 915-933.

Eriksen, E. O., \& Weigård, J. (2003). Understanding Habermas: Communicative action and deliberative democracy. London: Continuum.

Fearon, J. D. (1998). Deliberation as discussion. In J. Elster (Ed.), Deliberative democracy (pp. 44-68). Cambridge: Cambridge University Press.

Fleming, R. (1986). Adolescent reasoning in socio-scientific issues, part I: Social cognition. Journal of Research in Science Teaching, 23, 677-687.

Garrison, J. (1995). Deweyan pragmatism and the epistemology of contemporary social constructivism. American Educational Research Journal, 32(4), 716-740.
Gerrevall, P. (2003). Assessment of democratic competence — a pedagogical challenge [publ. in Swedish: Bedömning av demokratisk kompetens - en pedagogisk utmaning] Utbildning och demokrati, 12(3), 41-66.

Goodin, R. E. (2003). Democratic deliberation within. In J. S. Fishkin \& P. Laslett (Eds.), Debating deliberative democracy (pp. 5479). Malden, MA.: Blackwell.

Grace, M., \& Ratcliffe, M. (2002). The science and values that young people draw upon to make decisions about biological conservation issues. International Journal of Science Education, 24(11), 1157-1169.

Gutmann, A. (1999). Democratic education. Princeton, N.J.: Princeton University Press.

Habermas, J. (1984). The theory of communicative action. Vol 1: Reason and the rationalization of society. London: Heinemann Educational Books Ltd.

Habermas, J. (1987). The theory of communicative action. Vol 2: Lifeworld and system. Cambridge: Polity Press.

Habermas, J. (1990). Moral consciousness and communicative action. Cambridge, Mass.: MIT Press.

Habermas, J. (1993). Justification and application: Remarks on discourse ethics [Erläuterungen zur Diskursethik]. Cambridge, Mass.: MIT Press.

Habermas, J. (1996). Between facts and norms. Contributions to a discourse theory of law and democracy: Cambridge, Mass.: MIT Press.

Hickman, L. A. (2009). Pragmatism, constructivism, and the philosophy of technology. In L. A. Hickman, S. Neubert \& K. Reich (Eds.), John Dewey between pragmatism and constructivism (pp. 143161). New York: Fordham University Press.

Hodson, D. (2003). Time for action: Science education for an alternative future. International Journal of Science Education, 25(6), 645-671.

Kolstø, S. D. (2000). Consensus projects: Teaching science for citizenship. International Journal of Science Education, 22(6), 654-664.

Kolstø, S. D. (2001a). Scientific literacy for citizenship: Tools for dealing with the science dimension of controversial socioscientific issues. Science Education, 85(3), 291-310. 
Interest a tool for investigating deliberative qualities

Kolstø, S. D. (2001b). 'To trust or not to trust,... - pupils ways of judging information encountered in a socio-scientific issue. International Journal of Science Education, 23(9), 877-901.

Kolst $\varnothing$, S. D. (2006). Patterns in students' argumentation confronted with a riskfocused socio-scientific issue. International Journal of Science Education, 28(14), 1689-1717.

Kolstø, S. D., Bungum, B., Arnesen, E., Isnes, A., Kristensen, T., Mathiassen, K., et al. (2006). Science students critical examination of scientific information related to socioscientific issues. Science Education, 90(4), 632-655.

Kolst $\varnothing$, S. D., \& Ratcliffe, M. (2007). Social aspects of argumentation. In S. Erduran \& M. P. Jiménez-Aleixandre (Eds.), Argumentation in science education: Perspectives from classroom-based research (Chapt. 6). Dordrecht: Springer.

Kuhn, D., \& Udell, W. (2007). Coordinating own and other perspectives in argument. Thinking \& Reasoning, 13(2), 90-105.

Levinson, R. (2006). Towards a theoretical framework for teaching controversial socioscientific issues. International Journal of Science Education, 28(10), 1201-1225.

Lewis, J., \& Leach, J. (2006). Discussion of socio-scientific issues: The role of science knowledge. International Journal of Science Education, 28(11), 1267-1288.

Linder, C., Östman, L., Roberts, D. R, Wickman, P.-O. \& Erickson, G. L. (Eds.) (2010). Exploring the landscape of scientific literacy. London: Routledge.

Lundegård, I., \& Wickman, P.-O. (2007). Conflicts of interest: an indispensable element of education for sustainable development. Environmental Education Research, 13(1), 1-16.

Lundegård, I., \& Wickman, P.-O. (2009). Identity transformation in education for sustainable development: A question of location. Scandinavian Journal of Educational Research, 53(5), 461-479.

Millar, R., \& Osborne, J. (1998). Beyond 2000: Science education for the future. A report with ten recommendations. Retrieved 201304-03

from http://www.nuffieldfoundation.org/beyond2000-science-education-future

Nielsen, J. A. (2011). Dialectical features of students' argumentation: A critical review of argumentation studies in science education. Research in Science Education, DOI: $10.1007 / \mathrm{s} 11165-011-9266-\mathrm{X}$

OECD (2003). The PISA 2003 assessment framework . Mathematics, reading, science and problem solving knowledge and skills. Retrieved 2013-04-03from http://www.oecd.org/dataoecd/38/29/33707 226.pdf

Osborne, J., \& Dillon, J. (2008). Science education in Europe. Critical reflections. Retrieved 2013-04-03 from http://www.nuffieldfoundation.org/scienceeducation-europe

Öhman, J. \& Öhman, M. (2012). Participatory approach in practice: an analysis of student discussions about climate change. Environmental Education Research, DOI:10.1080/13504622.2012.695012

Öhman, J., \& Östman, L. (2007). Continuity and change in moral meaning-making - a transactional approach. Journal of Moral Education, 36(2), 151-169.

Östman, L. (2010). Education for sustainable development and normativity: a transactional analysis of moral meaningmaking and companion meanings in classroom communication. Environmental Education Research, 16(1), 75-93.

Pappas, G. F. (2008). John Dewey's ethics: Democracy as experience. Bloomington: Indiana University Press.

Ratcliffe, M. (1997). Pupil decision-making about socio-scientific issues within the science curriculum. International Journal of Science Education, 19(2), 167-182.

Ratcliffe, M., \& Grace, M. (2003). Science education for citizenship: Teaching socioscientific issues. Maidenhead: Open University Press.

Roberts, D. A. (2007a). Linné scientific literacy symposium opening remarks. In C. Linder, L. Östman \& P.-O. Wickman (Eds.), Promoting scientific literacy: science education research in transaction (pp 917). Retrieved 2013-04-03 from http://www.did.uu.se/carolineliberg/docum ents/070528ProceedingsScientificLiteracy_ 000.pdf

Roberts, D. A. (2007b). Scientific literacy/ science literacy. In S. K. Abell \& N. G. Lederman (Eds.), Handbook of research on science education (pp. 729-780). Mahwah: Lawrence Erlbaum Associates. 
Roth, W.-M., \& Barton, A. (2004). Rethinking scientific literacy. New York: Routledge.

Rudsberg, K. \& Öhman, J. (2010). Pluralism in practice - experiences from Swedish evaluation, school development and research. Environmental Education Research, 16(1), 115-131.

Sadler, T., Chambers, W., \& Zeidler, D. (2004). Student conceptualizations of the nature of science in response to a socioscientific issue. International Journal of Science Education, 26(4), 387-409.

Sadler, T. D., Barab, S. A., \& Scott, B. (2007). What do students gain by engaging in socioscientific inquiry? Research in Science Education, 37(4), 371-391.

Sadler, T. D., \& Donnelly, L. A. (2006). Socioscientific argumentation: The effects of content knowledge and morality. International Journal of Science Education, 28(12), 1463-1489.

Sadler, T. D., \& Zeidler, D. L. (2004). The morality of socioscientific issues: Construal and resolution of genetic engineering dilemmas. Science Education, 88(1), 4-27.

Shapiro, I. (2003). Optimal deliberation? In J. S. Fishkin \& P. Laslett (Eds.), Debating deliberative democracy (pp. 121-137). Malden, MA: Blackwell.

Simosi, M. (2003). UsingToulmin's framework for the analysis of everyday argumentation: Some methodological considerations. Argumentation, 17(2), 185-202.

Sjøberg, S., \& Schreiner, C. (2010). The ROSE project. An overview and key findings. Retrieved 2013-04-03 from http://roseproject.no./network/countries/nor

Toulmin, S. (1958/2003). The uses of argument. London: Cambridge Univ. Press.

Tytler, R., Duggan, S., \& Gott, R. (2001). Dimensions of evidence, the public understanding of science and science education. International Journal of Science Education, 23(8), 815-832.

Webster, S. (2008). How a Deweyan science education further enables ethics education. Science \& Education, 17(8), 903-919.

Wickman, P.-O. (2006). Aesthetic experience in making as situated talk and action. Mahwah, N.J.: Lawrence Erlbaum Associates.

Winch, C. (2006). Education, autonomy, and critical thinking. London: Routledge.

von Aufschnaiter, C., Erduran, S., Osborne, J., \& Simon, S. (2008). Arguing to learn and learning to argue: Case studies of how students argumentation relates to their scientific knowledge. Journal of Research in Science Teaching, 45(1), 101-131.

Wu, Y.-T., \& Tsai, C.-C. (2007). High school students informal reasoning on a socioscientific issue: Qualitative and quantitative analyses. International Journal of Science Education, 29(9), 1163-1187.

Young, I. M. (2003). Activist challenges to deliberative democracy. In J. S. Fishkin \& P. Laslett (Eds.), Debating deliberative democracy (pp. 102-120). Malden, MA.: Blackwell.

Zeidler, D. \& Nichols, B. (2009). Socioscientific issues: theory and practice. Journal of Elementary Science Education, 21(2), 4958.

Zeidler, D. L., Osborne, J., Erduran, S., Simon, S., \& Monk, M. (2003). The role of argument during discourse about socioscientific issues. In D. L. Zeidler (Ed.), The role of moral reasoning on socioscientific issues and discourse in science education (pp. 97-116). Dordrecht: Kluwer Academic Publishers.

Zeidler, D. L., Sadler, T. D., Simmons, M. L., \& Howes, E. V. (2005). Beyond STS: A research-based framework for socioscientific issues education. Science Education, 89(3), 357-377.

Zohar, A., \& Nemet, F. (2002). Fostering students' knowledge and argumentation skills through dilemmas in human genetics. Journal of Research in Science Teaching, 39(1), 35-62. science education: learning and meaning- 